\title{
Narcolepsy type 1 in an adolescent with vertical- acquired HIV infection - coincidence or potential
}

\section{trigger?}

Figure 1: Longitudinal weight curve

\section{Discussion}

\section{Background}

The underlying pathogenic mechanism of narcolepsy type 1 (NT1) is thought to be an autoimmune-mediated loss of hypocretin-secreting neurons. ${ }^{1}$

Epidemiological data reveal a clear association between NT1 and various infections. However, the association of HIV infection and narcolepsy has not been described so far..$^{2,3}$

- The presented case raises the hypothesis that HIV infection in a host with a distinct genetic susceptibility may trigger autoimmunemediated destruction of hypocretin-secreting neurons leading to NT1.

- This association has not been described so far possibly because NT1 is underdiagnosed in children and adolescents due to its less typical presentation in this population.

- Analysis of large HIV cohorts might answer the question whether there is a significant association with narcolepsy in children and adolescents infected with HIV.

\section{Case report}

15-year-old HIV positive boy presenting with excessive daytime sleepiness and weight gain (Figure 1).

HIV Diagnosis at the age of 8 years in Kinshasa. Uncomplicated course of HIV infection with fully suppressed viral load and no opportunistic infections under effective antiretroviral therapy (abacavir/ lamivudine/ ritonavirboosted-atazanavir)

No signs of anemia, thyroid gland dysfunction or CushingSyndrome; screening for illicit drug intake was negative.

Normal cerebral MRI showing no signs of HIV encephalopathy. No HIV replication in the CSF.
Polysomnography: increased sleep onset REM sleep periods (SOREMs) (3 of 4)

Multiple sleep latency test (MSLT): reduced sleep latency (mean 4 min and $22 \mathrm{~s})$.

Pathologically low hypocretin CSF level (orexin A $<20 \mathrm{pg} / \mathrm{ml}$ )

\section{Positive for HLA DQB1*06:02}

Diagnosis of NT1 confirmed according to the criteria of the $3^{\text {rd }}$ edition of the International Classification of Sleep Disorders (ICSD-3)
80

60

40

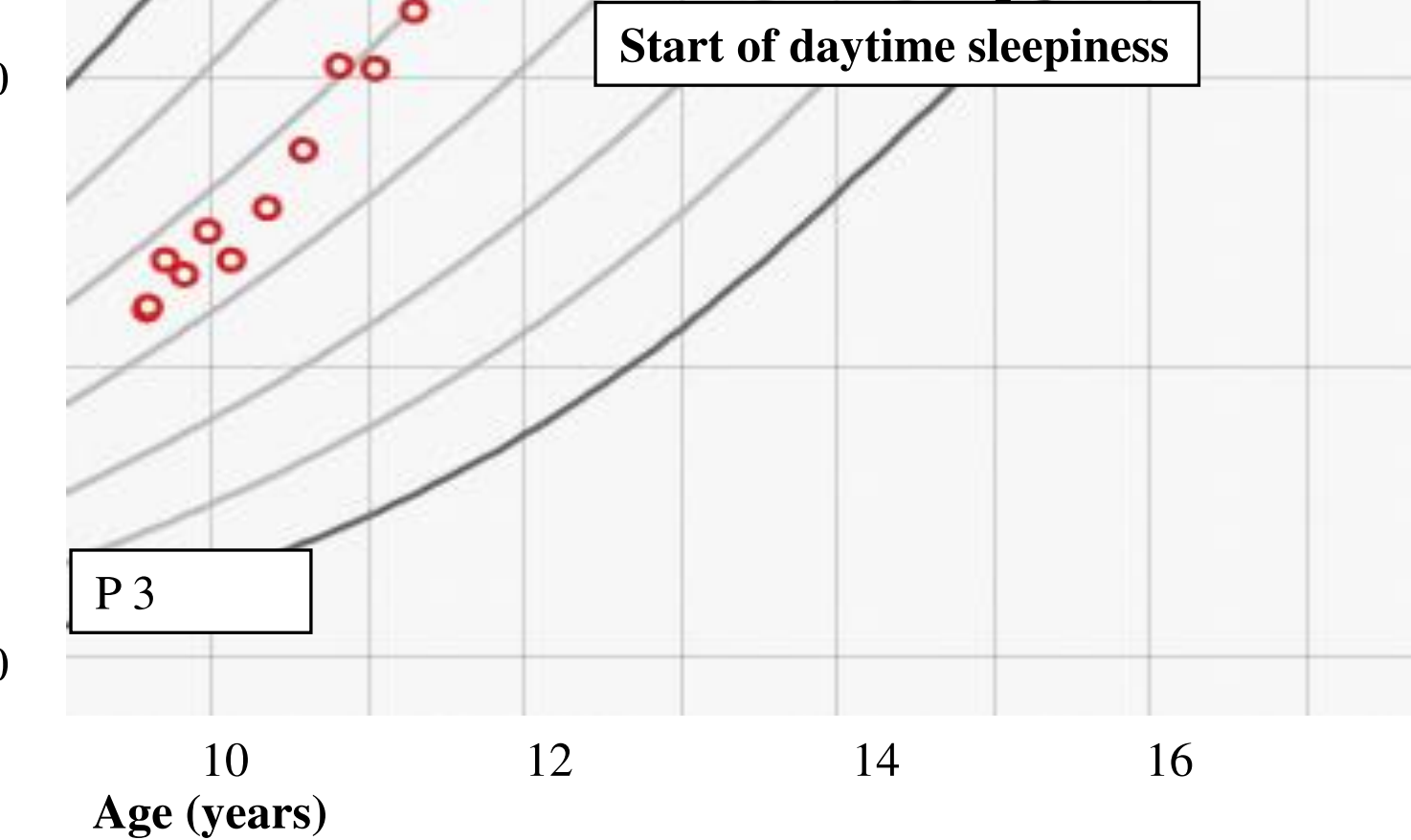

References 1. Fontana A, Gast H, Reith W, et al. Narcolepsy: Autoimmunity, effector T cell activation due to infection, or T cell independent, major histocompatibility complex class II induced neuronal loss. Brain. Oxford University Press; 2010;133:1300-11. 2. Han, F. et al. Narcolepsy onset is seasonal and increased following the $2009 \mathrm{H} 1 \mathrm{~N} 1$ pandemic in china. Ann. Neurol. $70,410-417$ (2011).
3. Picchioni D, Hope CR, Harsh JR. A case-control study of the environmental risk factors for narcolepsy. Neuroepidemiology. 2007;29(3-4):185-92. 